\title{
Arabic language teaching evaluation process for non-native speakers
}

\author{
Taqi Eddin M. Abdelbaset ${ }^{\mathrm{a}, 1, *}$, Nidal A.M Jabari ${ }^{\mathrm{b}, 2}$ \\ ${ }^{a}$ Department of Arabic Language Palestine Technical University Kadoorie, Palestine \\ ${ }^{\mathrm{b}}$ Department of Computer Palestine Technical University Kadoorie, Palestine \\ ${ }^{1}$ taqitammi@gmail.com*; ${ }^{2}$ nidal.jabari@ptuk.edu.ps \\ * corresponding author
}

\section{ARTICLE INFO}

\section{Article history}

Received 2020-06-29

Revised 2020-08-30

Accepted 2020-09-28

\section{Keywords}

Achievement tests

An-Najah University

Aptitude test

Measurement

Evaluation

\begin{abstract}
Teaching languages in general and teaching Arabic to non-native speakers, in particular, have had two attempts to create a standardized test to assess language proficiency in Arabic for non-native speakers. This research is a comparative and descriptive study of the reality of the achievement tests carried out by An-Najah National University in Palestine at the College of Arts, Department of Arabic Language Teaching Non-Native Speakers, as it has been the leading educational institution established in the State of Palestine for decades. The need for courses on preparing the correct tests for students comes through seminars or conferences or a direct meeting between the teacher and the authors of questions for the Arabic language test for speakers of other languages. The preparation of the exam requires a specific skill and knowledge of the circumstances of the learners and the variations between them so that questions can be with a challenging level with a low percentage, middle-level questions, and they are the most and simple questions to answer directly, these questions can be at the beginning of the exam to give a boost to the student who takes the exam.
\end{abstract}

This is an open access article under the CC-BY-SA license.

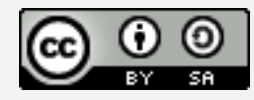

\section{Introduction}

The tests are one of the important means that are used in measuring and evaluating to know the learners' abilities and achievement levels [1], and the extent of achieving behavioral goals and educational outcomes. Specialists consider that the tests are the final stage of the activities that the teacher provides in the study phase that will help to raise the achievement of the learner, and the various educational institutions, centers, and bodies are keen on building a test that is in line with international standards, by preparing educators specialized in the science of education, measurement and evaluation.

There are many varied opinions, also there are many studies, experiences and attempts to spread Arabic and teach it to Non-native speakers. Modern education literature indicates the role of tests as the main measurement tool [2], and that building, implementing, and using the test meets the needs of learners and their behavior, it also achieves the desired education goals in the educational process. The test must be built on the basis of clear scientific studies away from randomness in order to motivate students and develop their belonging to education [3]. There have been numerous and various studies that indicate the foundations related to the formulation of tests for non-Arabic speakers and their reality [4], taking in consideration the various skills that underpin the standardized tests which are reading, listening, writing, and speaking. 
The idea of this research based on monitoring the experiences of institutions and universities specialized in teaching Arabic to speakers of other languages, and the most prominent beneficiary of the results of this study are the academic bodies, from schools, institutes and universities, that work to attract students who are non-native speakers.

Teaching languages in general and teaching Arabic to Non-native speakers in particular had two attempts to build a standardized test for measuring language proficiency in the Arabic language for Non-native speakers. The first is the Sami Hanna Test and the second in University of Michigan Exam (1974). After these two tests, the study of Rushdi Taima [5] on the use of the complement test to measure the language proficiency among Arabic language students in some American universities is considered one of the first studies that aimed to measure the language proficiency in the Arabic language for non-native speakers. On the next year Muhammad Sheikh (1988) presented a research on the proficiency tests, he presented a comprehensive test to measure the language proficiency in the Arabic language for non-native speakers of the four language skills, similar to the TOEFL IBT tests in the English language.

In a previous study, Iman Haridy employed the criteria mentioned in the language proficiency manual with the aim of building a placement test for Arabic Non-native speakers [6]. The IBT test as a tool in IBT tests in the English language is an experience that can be used in the field of teaching Arabic to Non-native speakers, but there are two aspects of the IBT tests that do not match the nature of the Arabic language, namely: The first aspect: IBT tests do not measure the student's ability to speak directly, which is not consistent with the nature of the Arabic language, especially with regard to measuring the student's ability to pronounce adjacent sounds in the pronunciation that is specific to the Arabic language. Speaking also provides information about the examiner used to predict future success in daily conversations about needs, self-expression, and opinions [7].

The second aspect: IBT tests include indirect tests in writing, depend on the test of separate units in the rules and vocabulary, this type of writing tests does not provide clear evidence of writing capabilities, while the best way to measure writing skill is the indirect test, where it is required that the students write an essay, specifying the points to be measured accurately. For example: ability to perform linguistic, creative, imaginative, and intelligent [8]. Hence, it is important to stress the importance of taking the test into account speaking and writing skills in order to reach an accurate estimate of the level of competence of the examiner in the Arabic language for non-native speakers [9].

When talking about proficiency tests in the Arabic language for non-native speakers, this requires that the examiner have a set of criteria describing degrees of language proficiency, so that the test can be built on a scientific basis. Language Proficiency Standards issued by the American Association for the Teaching of Foreign Languages [10] on language proficiency standards are among the oldest attempts to develop language performance specifications and set them as standards that benefit curriculum developers and designers of language proficiency tests.

Interest began to standardize language proficiency standards in Arabic at the Association of Foreign Language Teachers (ACTFL) in the United States in 1989, the Association issued the Arabic Proficiency Guide (ACTFL Proficiency Guidelines, 1989), which divides levels of proficiency in the Arabic language into ten levels from beginner to Super, and set standards for proficiency in Arabic language skills, at every level. Researches summarizes that some general principles that must be observed when developing a proficiency test in the Arabic language for non-native speakers: (1) Determining the sources of language proficiency standards in the Arabic language, the researchers may rely on previous criteria to describe levels of language proficiency, or he may derive other criteria in light of previous standards, or derive it by reviewing Arabic education books [11]. (2) The competency criteria include a description of the four language skills, this means that the levels of language proficiency, from beginner to advanced level, include an accurate standard for each of the four language skills. (3) The standards provide the strengths and weaknesses of the linguist, and provide justifications for that as much as possible. In other words, the standards describe what the student can perform linguistically, and what the student cannot - or find difficulty - in his performance. (4) Taking into account the elements associated with language learning; like culture, social and cognitive processes. Standards and tests for linguistic proficiency should not focus on describing the linguistic performance only of lexical knowledge, knowledge of sounds and grammar, but rather 
should address everything related to the communicative function of language, the role of the cultural aspect, and competence in the national language of the learner [12]. (6) Determine the relationship between the use of certain expressions or linguistic affinities and the level of competence expressed in this use; This is intended to determine the level of proficiency that expresses the learner's use of the sayings and expressions expressed in the Arabic language, and to determine the level of competence that expresses the use of links in the Arabic language, or what are known as speech marks in English language lessons [13].

The tests directed for non-Arabic speakers are many, the Internet includes information on thousands of samples of tests, and these tests differ according to the goals and directions, it is possible to find more about these types of tests in [22]. The researchers reviewed many of these tests that may be compatible with international standards may differ from them. This situation is considered randomness of the tests as they differ according to the different institutions, centers or individuals, so this study was to show the following: What are the characteristics of a good test? What are the language proficiency tests used in teaching Arabic to speakers of other languages? What kinds of tests? What are the steps for exam preparation? How to analyze tests and measure language skills? Is it possible to set scientific standards to standardize language proficiency tests in teaching Arabic to speakers of other languages? What is the role of official institutions in drafting the tests, An-Najah National University as a model?

This study is expected to be descriptive and comparative of the reality of the tests directed to nonArabic speakers, and the extent of their compatibility with international specifications. The study will be divided into two chapters, namely: The theoretical framework that includes the foundations for preparing the selection, its skills and objectives. The applied framework that includes the reality of the Arabic language tests at An-Najah National University, and their compatibility with international standards.

\section{Method}

The test specifications should have: honesty, consistency, and objectivity [17]. Honesty is that the test achieves the goal that was in itself, consistency is to give the same result in the case of repetition for another group of individuals (European reference framework, and objectivity means nonintervention with the test. (http://www.khayma.com/education).

The tests vary according to the classification [18], including topical and essay tests, as well as projective tests, such as psychological and personal tests, and academic achievement tests, and the tests are also practical and linguistic [17], and they are Likewise, individually and collectively, they are also quick to answer, or need a long time, but in terms of the way the results are interpreted, the tests are test-referenced, or standard reference [17], and the test may be considered specialists from the measurement and testing centers, The way it is applied and corrected is as uniform as possible for all testers [19]. The researchers monitored a set of sample tests on the Internet for non-Arabic speakers, ranging from essay and substantive questions, including: Converting numbers to words, such as: On the bus: 18 passengers. ( https://www.zyadda.com/convert-numbers-to-writing/)

The process of teaching Arabic for speakers of other languages can be effective through some overlapping factors; teachers' characteristics, learners' characteristics, program, programs' ability to meet the learners' needs and the audio-visual aids. These factors should integrate and work harmoniously in order to give the desired results. The test is also good if the goals are well defined, the content is analyzed, the specification table is prepared, applied to a pilot sample and corrected for the first time and then for the second time. In the end, I analyze the results and know the weaknesses and strengths, and the best language tests that measure the skill of reading, writing, speaking and listening [23].

As for the question: What progress has Al-Najah University made in this field?

Dr. Raed Abdel-Rahim, Director of the Institute for Teaching Arabic Language at An-Najah University and founder of the Institute, answered that the development that has occurred in the program for teaching Arabic to non-Arabic speakers at An-Najah University is not related to the student, rather it is related to the exams organized by An-Najah National University, which are: The university obtained recognition From the Greek Parliament with the Proficiency Exam, and thus the 
exam is within the European Union system and takes an international character, as the exam is organized twice a year in Greece, and the various advertisements in Greece require the student to pass the Proficiency Exam at An-Najah University to obtain an Arabic language certificate, and the exam is framed according to International standards and the European standard in form and content, and this gave An-Najah University a remarkable development in this aspect that distinguishes it from other Arab and international universities in teaching Arabic to speakers of other languages.

\section{Results and Discussion}

Many educators agree on the definition of the test as: "A set of questions that students are asked to respond to in order to measure their levels in a particular language skill, and to explain the extent of its progress in it and compare it with colleagues [14]. It aims to measure individuals and their knowledge in a specific field, and that it is a systematic procedure for measuring a sample of individuals 'behavior [15]. The test must measure an intended thing such as giving a degree, value, rank, etc. The goal of the test is always to measure or evaluate intended thing. (Http://uqu.edu.sa).

This study examines the final results related to teaching Arabic to speakers of other languages, we tend to define the test as: An organized method for comparing the behavior of two or more people with the aim of reaching accurate results related to the education of Arabic for non-native speakers [16]. One of the tests and its content will be recognized at An-Najah National University [21]. The department of teaching Arabic to non-native speakers was established at An-Najah University on 2011. This program is distinguished by focusing on the previous four skills, namely: reading, writing, listening and speaking. The university takes a test to determine the student level. Professors specialized in teaching Arabic to non-native speakers are managing this department. The department has a course in it that goes beyond the goal of education to exchange linguistic and cultural knowledge, beside a special library has books to teach Arabic to non-native speakers.

In this department, the Arabic language and its literature are taught in four levels, namely: The first level, in which students are found, teaching them to read, write and pronounce Arabic sounds correctly, and distinguish between similar Arabic letters, such as: "Sein(s)" and "Shin(ş)", then students move to vocabulary, Arabic grammar, vocalization, reading simple sentences and using the dictionary. The second level, in which the student is connected to the linguistic reality, and expressing his need, for example: getting acquainted, searching for an apartment, in the restaurant, at the doctor, in the mall, a popular wedding, visiting a friend, visiting a patient, in the bank, etc., and forming simple sentences of four to five sentences.

The third level, in which the student reads texts on various topics for more practice, including social, political, economic, religious, environmental and literary topics, and reading the Arab press, this is the phrase,, knowledge of the nominal sentence, "kana"(was) and its sisters , 'Inna" and its sisters, then lessons and patterns of morphology and syntax from the of the subject, object, source and preference, focusing on teaching them on both sides, theoretical and practical, preferably to be presented through texts or applied to texts studied by students. at the end the students read a text that is not included in this stage that needs to be developed and strengthened. The fourth level, which is the end of these stages of study contains a feedback from the previous ones, then the final exam will be executed, as we will mention later.

\subsection{Achievement tests, reality and standards}

The tests at An-Najah University vary between proficiency tests to know the level of learners in Arabic in light of their accumulated previous experiences, i.e. to the adequacy of the learner in carrying out the work required of him in the future. In this study, reference will be made to the first level: a1, which is one of Dialal's measures of linguistic assessment which is an application of the general European frame of reference for diagnostic purposes. The system also provides advice to learners on how to improve their language skills in addition to making them as language learners more aware and also of the evaluation procedures [8].

\subsection{Building language proficiency tests for non-native speakers at An-Najah University}

First, reading, in which the learner can read very short simple texts that contain well-known names and words, distinguish between names and words, and understand simple short phrases for example in postcards. Second, writing, here a non-Arabic speaking student can write simple information to 
friends, such as: describing a residential place, personal data or simple sentences [8]. Third, understanding audio texts. The learner can understand daily life phrases, simple and direct needs, answer questions, answer others, address them, and know their words [20].

According to the theoretical and the practical frameworks the researchers concluded the following points regarding the Arabic language test for non-native speakers. The test should be based on sound foundations and systems in order to be of global credibility in terms of content; Because many of the tests directed to non-Arabic speakers do not observe the principles of measurement and evaluation, we can call them random tests [24]. Through careful review, the researchers noted the existence of an international standard for evaluating the extent of the ability of non-Arabic speakers to obtain cognitive achievement, this criterion is adopted in the European Cooperation Council. The general European frame of reference for languages. The researchers relied on it for discovering the assessment of achievement.

The design of the tests is one of the most important stages; It is the ultimate goal of education, to know the extent to which educational goals are achieved, and the design of the test needs knowledge of the principles of measurement and evaluation, therefore the test varies from objective questions to the article, and objective questions should vary to include: right and wrong questions, multiple choice, and matching or approval questions. Analyzing the results helps to know how difficult the question is. Because the questions for which the answer rate is $100 \%$ complete are considered incorrect questions due to their ease, they should not be among the questions, as well as questions for which the answer rate for them is negative or very few, or the arithmetic mean for them reaches a degree close to zero that is excluded or knowledge the reason why there is no answer to it, and here comes the importance of testing the exam on one or more samples and knowing the stability percentage.

\section{Conclusion}

The necessity of holding courses on how to preparing the proper tests for students and this comes through seminars or conferences or a direct meeting between the trainer and the authors of the questions for the Arabic language test for speakers of other languages. The exam preparation needs a specific skill and knowledge of learners' conditions and the individual differences between them. These questions can then be submitted according to these factors, with difficulty level middle level or easy questions to be answered directly. These questions can be at the beginning of the exam to boost the student who takes the exam establishing an educational question bank in all educational institutions that teach Arabic to other languages speakers. The questions are prepared by specialists in the science of measurement and evaluation, these questions are varied, and the teacher can train students on models of them to prepare for the examination, not to create a surprise element for the student.

\section{Acknowledgment}

The researchers thank Palestine Technical University Kadoorie for its continuous support for their scientific research and its follow-up and dissemination of results

\section{References}

[1] Testing, Teaching, and Learning,A Guide for States and School Districts (1999), Ebook Formats: ePub, Kindle/MobiPocket, available at: Books Google.

[2] Karine Tremblay, Diane Lalancette, Deborah, Roseveare Assessment of Higher Education Learning Outcomes Feasibility Study Report Volume 1 - Design and Implementation, OECD 2012, available at: Google Scholar.

[3] Linda Darling-Hammond,Lisa Flook,Channa Cook-Harvey,Brigid Barron \&David Osher,Implications for educational practice of the science of learning and development,Pages 97-140,Published online: 17 Feb 2019, doi: 10.1080/10888691.2018.1537791.

[4] Koda, Keiko. Insights into second language reading: A cross-linguistic approach. Cambridge University Press, 2005, available at: Books Google. 
[5] Toeimah,R: The Use of Cloze to Measure the proficiency of Students of Arabic as a Second Language in Some Universities of Minnesota, 1978, available at: Google Scholar.

[6] Handbook for Arabic language teaching professionals in the 21st century (2006): 139-155, available at: Books Google.

[7] Underhill,N: Testing Spoken Language: A handbook of oral testing techniques. Cambridge University Press. 1991, available at: Books Google.

[8] Hughes, A. (1989). Testing for language teachers. Cambridge: Cambridge University Press, available at: Google Scholar.

[9] ETS, Educational Testing Service, 2006, The Official Guide to the New TOEFL iBT, available at: Google Scholar.

[10] ACTFL Arabic proficiency guidelines (September 1989), journal of the American Council on the teaching of foreign languages, Volume 22, Number 4, doi: 10.1111/j.1944-9720.1989.tb02760.x

[11] Gomez, Pablo Garcia. Noah, Aris. Schedl, Mary. Wright, Christine. Yolkut, Aline: Proficiency Descriptors Based on a Scale- Anchoring Study of the new TOEFL iBt Reading Test, Language Testing, v24 n3 p 417- 444 2007, doi: 10.1177/0265532207077209.

[12] Albantani, Azkia Muharom, and Ahmad Madkur. "" Musyahadat Al Fidyu": YouTube-Based Teaching and Learning of Arabic as Foreign Language (AFL)." Dinamika Ilmu 17.2 (2017): 291-308, available at: Eric.ed.gov.

[13] Ming Wei. Acomparative Study of the Oral Proficiency of Chinese Learners of English Across Task Functions: A Discourse Marker Perspective. Foreign language Annals, Vol. 44, No.4. 2011, doi: 10.1111/j.1944-9720.2011.01156.x.

[14] Rushdie Ahmed To'eima, Dalil 'Amal fi I'dad al-Mawad al-Ta'limiyyah li Baramij Ta'lim al-Lughoh al'Arabiyyah, Makkah Mukarromah: Jami'ah Ummul Qura, 1985, available at: Google Scholar.

[15] Wahba, Kassem, Zeinab A. Taha, and Liz England, eds. Handbook for Arabic language teaching professionals in the 21st century. Routledge, 2014, doi: 10.4324/9781315676111.

[16] Ali, Ahmed Ali Badri. The Use of ICT to Enhance Learning of Arabic Language for Non-Native Speakers. Diss. Sudan University of Science \& Technology, 2019, doi: 123456789/23849.

[17] Ali, A., S. Ezeadi, and N. J. Ogbazi. "Introduction to educational measurement and evaluation." (1988): 10-20, available at: Google Scholar.

[18] Frey, Bruce B., ed. The SAGE encyclopedia of educational research, measurement, and evaluation. Sage Publications, 2018, available at: Google Scholar.

[19] Allam, Salahuddin, educational and psychological tests and measurements, Dar Al-Fikr, Jordan, p. 1, 2006, available at: Google Scholar.

[20] Trim, John LM. "Modern languages in the Council of Europe 1954-1997." Council of Europe Language Policy Division (2007), available at: Google Scholar.

[21] https://learnarabic.najah.edu/ar/

[22] https://learnarabic.najah.edu/en/registration/arabic-international-proficiency-exam/

[23] Basma A. S. Dajani, Difficulties of learning Arabic for non-native speaker , Procedia - Social and Behavioral Sciences ,University of Jordan , February 2014, doi: 10.1016/j.sbspro.2013.12.808.

[24] N. M. Al-Assaf and K. M. Al-Wazzan, "Foundations of designing arabic for non-native speakers' tests," Dirasat Hum. Soc. Sci., 2014, available at: Google Scholar. 